\title{
COVID-19 Pandemisi Sürecinde Hemşirelik Öğrencilerinin Çevrimiçi Öğrenmeye Yönelik Görüş ve Tutumları
}

\author{
Yeter ŞENER ${ }^{1}{ }^{1}$, Ayşe ŞENER TAPLAK ${ }^{1}{ }^{1}$, Rukiye HÖBEK AKARSU ${ }^{1}$
}

Öz

Amaç: $\mathrm{Bu}$ araştırmada hemşirelik öğrencilerinin çevrimiçi öğrenmeye yönelik görüş ve tutumlarının belirlenmesi amaçlandı.

Gereç ve Yöntemler: Araştırma 2020-2021 eğitim öğretim yılında bir Sağlık Bilimleri Fakültesi'nin hemşirelik bölümünde öğrenim gören 312 öğrenci ile gerçekleştirildi. Veri toplama aracı olarak tanıtıcı özellikler veri formu, hemşirelik eğitiminde çevrimiçi öğrenmeye ilişkin görüşler formu ve çevrimiçi öğrenme tutum ölçeği (ÇÖTÖ) kullanıldı. Veriler tanımlayıcı istatistiksel analizler ve nonparametrik testler ile değerlendirildi.

Bulgular: Hemşirelik öğrencilerinin \%59,9'unun hemşirelik eğitiminde örgün eğitimi tercih ettiği belirlendi. Öğrencilerin \%76,9'unun çevrimiçi dersleri cep telefonu ile takip ettiği saptandı. Öğrencilerin genel kabul, bireysel farkındalık, kullanışlılık ve uygulama etkililiği alt boyut puanlarının sırasıyla $21,61 \pm 5,42,17,49 \pm 6,60,9,44 \pm 3,70,13,97 \pm 3,16$ ve ÇÖTÖ toplam puanın $62,53 \pm 17,22$ olduğu belirlendi. Yaşa göre genel kabul, kullanışlılık alt boyut puanları ile ÇÖTÖ toplam puanı arasında fark tespit edildi. Erkek öğrencilerin genel kabul, bireysel farkındalık alt boyut puanlarının kız öğrencilerden daha yüksek olduğu saptandı. ÇÖTÖ alt boyut puanları ve toplam puanı yüksek olan öğrencilerin hemşirelik eğitiminde çevrimiçi öğrenmeye ilişkin olumlu görüş bildirdikleri belirlendi.

Sonuç: Bulgular doğrultusunda hemşirelik eğitiminde çevrimiçi öğrenmenin örgün eğitimi destekleyici bir öğretim yöntemi olarak kullanılması önerilebilir.

Anahtar kelimeler: Hemşirelik; tutum; eğitim.

\section{Views And Attitudes of Nursing Students Towards Online Learning During COVID-19 Pandemic}

\section{ABSTRACT}

Aim: This study aims to find out the views and attitudes of nursing students towards online learning.

Material and Methods: The study was carried out with 312 students studying in a Department of Nursing at a Faculty of Health Sciences in the 2020-2021 academic year. Introductory features data form, online learning opinions form in nursing education and online learning attitude scale (OLAS) were used as data collection tools. Data were assessed through descriptive statistical analysis and nonparametric tests.

Results: It was determined that $59.9 \%$ of nursing students did not prefer online learning in nursing education. It was determined that $76.9 \%$ of the students followed the online lessons by their mobile phones. The sub-dimension scores of the general acceptance, individual awareness, usefulness and application effectiveness of the students participating in the study were $21.61 \pm 5.42,17.49 \pm 6.60,9.44 \pm 3.70,13.97 \pm 3.16$ and the total score of OLAS was found to be $62.53 \pm$ 17.22 respectively. It was determined that difference between students age the general acceptance, usefulness subdimension scores and the total score of OLAS. It was determined that the general acceptance and individual awareness

1 Yozgat Bozok Üniversitesi, Sağlık Bilimleri Fakültesi, Yozgat, Türkiye

Sorumlu Yazar / Corresponding Author: Yeter ŞENER e-mail: yeter.sener@yobu.edu.tr

Geliş Tarihi / Received: 25.01.2021, Kabul Tarihi / Accepted: 02.12.2021 
sub-dimension scores of male students were higher than female students. It was determined that the students with high sub-dimension scores and total score of OLAS reported positive opinions about online learning in nursing education.

Conclusion: In line with the findings from the study, it is recommended that online learning methods be adopted as teaching methods that assist formal education in nursing.

Keywords: Nursing; attitude; education.

\section{GIRIS}

Günümüzde tüm dünyayı etkisi altına alan ve halen devam etmekte olan COVID-19 (Coronavirüs) pandemisi sağlık, sosyal ve ekonomi alanlarını etkilediği gibi eğitim sistemlerinde de küresel boyutta büyük bir değişime neden olmuştur (1-3). Dünyada ve Türkiye'de pandeminin etkilerinden korunmak amacıyla çeşitli önlemler alınmıştır. Türkiye'de ilk vaka 10 Mart 2020 tarihinde bildirilmiş ve 16 Mart 2020 tarihi itibariyle tüm öğretim kurumları ile birlikte yükseköğretim kurumlarında da eğitime ara verilmiştir (4). Birleşmiş Milletler Eğitim, Bilim ve Kültür Kurumu (UNESCO) verilerine göre, pandemi sürecinde alınan tedbirler gereği eğitim kurumlarının kapatılmasından dolayı dünya çapında 190'dan fazla ülkede yaklaşık 1,6 milyar öğrenci, bir diğer ifade ile dünya öğrenci nüfusunun \%94'ü süreçten etkilenmiştir (5). Pandemi sürecinde COVID-19 yüksek virülansına karşı insanların can güvenliğini riske atmadan eğitim faaliyetlerini sürdürmek için ilk akla gelen seçenek teknolojik imkânlara başvurmak olmuştur. Dünyanın pek çok ülkesinde ve Türkiye'de örgün eğitime ara verilerek uzaktan eğitime geçilmiştir (6).

Günümüzde uzaktan eğitim, yükseköğretim kurumlarındaki eğitim-öğretim faaliyetlerinin bilgi teknolojilerine dayalı olarak yürütüldüğü, mekândan bağımsızlığın sağlandığı, öğrenci ve öğretim elemanı etkileşimine imkân sunan bir eğitim yöntemidir (6-8). Çevrimiçi öğrenme, dünya çapında çeşitli veri tabanları kullanılarak bilgisayar ağları üzerinden gerçekleştirilen öğrenmedir (9). Türkiye'de hemşirelik lisans programında uzaktan eğitim zorunlu olarak kullanılan bir öğretim yöntemi olmamakla birlikte, daha önce lisans tamamlama amacıyla hemşirelik eğitiminde tercih edilmiştir $(10,11)$. Ancak günümüzde tüm dünyayı etkisi altına alan COVID-19 pandemisi çevrimiçi öğrenmeyi hemşirelik eğitimi için bir tercihten ziyade zorunlu bir deneyim haline getirmiştir (12-16).

Amerikan Hemşirelik Akreditasyon Birliği (AACN) tarafından uzaktan eğitime ilişkin yayınlanan bildiride, hemşirelik eğitiminde uzaktan eğitim yolu ile verilen ders ve programların giderek arttığını, bu ihtiyacı kabul ederek daha kaliteli hemşirelik eğitiminin sağlanması için bazı standartların belirlenmesinin gerekli olduğu bildirilmiştir (17). Bununla birlikte uzaktan eğitim ortamlarının geliştirilmesinde gerekli tüm ölçütler sağlansa dahi öğrenenin bu ortamlara karşı tutum ve yaklaşımları oldukça önemlidir (18). COVID-19 pandemisinin küresel boyutta devam ettiği günümüzde hemşirelik eğitiminde çevrimiçi öğrenmenin kullanımına ilişkin öğrencilerin görüş ve tutumlarının belirlenmesi sürece yön vermek açısından önem arz etmektedir.
$\mathrm{Bu}$ araştırma, hemşirelik öğrencilerinin çevrimiçi öğrenmeye yönelik görüş ve tutumlarının belirlenmesini amaçlamaktadır.

\section{GEREÇ VE YÖNTEMLER Araştırmanın Türü}

$\mathrm{Bu}$ araştırma, 2020-2021 eğitim öğretim yılında kesitsel bir araştırma olarak gerçekleştirildi.

Araştırmanın Yapıldığı Yer ve Özellikleri

Araştırma İç Anadolu Bölgesi'nde yer alan bir Sağlık Bilimleri Fakültesi'nde Ekim-Kasım 2020 tarihleri arasında yürütüldü. Araştırmanın yapıldığı ilgili fakültede örgün eğitim sistemi mevcuttur. COVID-19 pandemisi nedeniyle Mart 2020 itibariyle uzaktan eğitime geçilmiştir.

\section{Araştırmanın Evren ve Örneklemi}

Araştırmanın evrenini belirtilen tarihlerde Sağlık Bilimleri Fakültesi'nde eğitim öğretim gören 450 hemşirelik öğrencisi oluşturdu. $\mathrm{Bu}$ öğrencilerden, araştırmaya katılmayı kabul eden ve kayıt dondurmamış 312 öğrenci araştırmanın örneklemini oluşturdu. Evreni oluşturan öğrencilerin \%69,3'ü araştırmaya katıldı.

\section{Verileri Toplama Araçları}

Tanıtıcı Özellikler Veri Formu; araştırmacılar tarafından hazırlanan formda öğrencilerin yaşı, cinsiyeti, medeni durumu, sınıfı, yaşadığı yer, evde kendisine ait odası, bilgisayarı ve interneti olma durumu, çevrimiçi derslere katılmak için kullanılan cihaz, çevrimiçi öğrenme yolu ile eğitimin takip edildiği yere ilişkin sorular yer aldi.

Hemşirelik Eğitiminde Çevrimiçi Öğrenmeye İlişkin Görüşler Formu; literatür taraması sonucunda (19-22) araştırmacılar tarafından hazırlanan formda öğrencilerin; hemşirelik eğitiminde tercih ettiği öğretim yöntemi, çevrimiçi öğrenmenin hemşirelik mesleğinin kazandırılmasında kullanılabilir bir eğitim-öğretim yöntemi olup olmadığı, çevrimiçi öğrenmeyi yararlı bulma/bulmama ve nedenleri, hemşirelikte uygulamalı meslek derslerinin çevrimiçi yürütülmesinin ve hemşirelikte uygulamalı derslerin teorik ile uygulamasının eşgüdümlü gitmemesinin öğrenme verimliliğini etkileme durumu, çevrimiçi öğrenmede hemşirelik derslerine hazırlık için ayrılan zaman, çevrimiçi öğrenme süresince hemşirelik dersleri ile ilgili makale/kitap/araştırma raporu okuma oranı ile hemşirelik derslerine olan ilgi durumuna ilişkin sorular yer ald1.

Çevrimiçi Öğrenme Tutum Ölçeği (ÇÖTÖ); Usta ve arkadaşları (2016) tarafından geliştirilen ölçek üniversitelerin lisans programlarında eğitim alan öğrencilerin çevrimiçi öğrenmeye karşı tutumlarını ölçmektedir. Ölçek 5'li likert tipinde olup, toplam 20 maddeden ve 4 alt boyuttan oluşmaktadır (18). Ölçekten alınabilecek puan 20 ile 100 arasında değişmektedir. Elde edilen puanın yüksekliği oranında öğrenciler olumlu tutuma sahiptir $(18,23,24)$. Ölçek Cronbach alpha güvenirlik katsayısı genel kabul alt boyutu için 0,77 , bireysel farkındalık alt boyutu için 0,85 , kullanışlılık alt boyutu için 0,79 uygulama etkililiği alt boyutu için 0,68 ve tüm ölçek için 0,904 olarak bulunmuştur (18). Bu araştırmada ise, Cronbach alpha güvenirlik katsayısı genel kabul alt boyutu için 0,77, bireysel farkındalık alt boyutu için 0,74, kullanışl1lık alt boyutu için 0,81, 
uygulama etkililiği alt boyutu için 0,83 ve tüm ölçek için 0,898 olarak saptand1.

\section{Ön Uygulama}

Veri toplama araçlarının ön uygulaması ilgili fakültede öğrenim gören ve araştırmaya katılmayan 20 hemşirelik öğrencisi ile çevrimiçi anket uygulaması yöntemi ile gerçekleştirildi. Öğrencilere soruların anlaşılırlığını ' $a c ̧ ı k$ anlaşılır, düzenlenmesi gerekir, anlaşılır değil' şeklinde değerlendirmesi istendi. Yapılan değerlendirme sonucunda öğrencilerden 'anlaşılır değil' bildirimi alınan sorular tekrar gözden geçirilerek veri toplama araçlarına son şekli verildi.

\section{Verilerin Toplanması}

Veri toplama araçları bilgisayar ortamında çevrimiçi anket uygulaması ile hazırlandı. Çevrimiçi anketin ilk bölümü araştırmanın amacının açıklanması ve bilgilendirilmiş gönüllü oluruna ayrıldı. İkinci bölüm öğrencilerin tanıtıcı özelliklerine ilişkin, üçüncü ve son bölüm ise hemşirelik eğitiminde çevrimiçi öğrenmeye ilişkin görüşler ile çevrimiçi öğrenme tutumlarına ayrıldı. Hazırlanan veri toplama formuna ilişkin link öğrenci gruplarında paylaşıldı. Verilerin toplanması tamamlandıktan sonra verilerin değerlendirilmesi aşamasına geçildi.

\section{Verilerin Değerlendirilmesi}

Veriler IBM SPSS Statistics Standard Concurrent User V 22 (IBM Corp., Armonk, New York, ABD) istatistik paket programında değerlendirildi. Tanımlayıcı verilerin analizinde standart sapma, aritmetik ortalama, ortanca, minimum, maksimum, sayı ve yüzde değerleri kullanıldı. Verilerin normal dağılıma uygunluğu Shapiro Wilk testi ile değerlendirildi. Normal dağılıma uymayan verilerin değerlendirilmesinde Mann-Whitney $U$ ve KruskalWallis testleri kullanıld1. $p<0,05$ istatistiksel olarak anlamlı kabul edildi.

\section{Araştırmanın Etik Boyutu}

Araştırmaya başlamadan önce araştırmanın yapıldığ kurum ve etik kuruldan (Karar Numarası: 2017-KAEK189_2020.09.23_06) gerekli izinler alındı.

\section{BULGULAR}

Araştırmada hemşirelik öğrencilerinin \%76,0'ının kadın, \%55,4'ünün 21-24 yaş aralığında, \%98,7'sinin bekâr olduğu belirlendi. Öğrencilerin \%30,1'inin dördüncü sınıf, \%26,9'unun üçüncü sınıf öğrencisi olduğu ve $\% 46,2$ 'sinin ilde yaşadığı saptandı. Öğrencilerin $\% 55,1$ 'inin evinde kendisine ait odas1, \%56,1'inin evinde bilgisayarı ve \%66,3'ünün evinde interneti olduğu belirlendi. Öğrencilerin \%76,9'unun çevrimiçi derslere cep telefonu ile katıldığ $1, \% 97,1$ 'inin çevrimiçi öğrenme yolu ile eğitimini evinden takip ettiği tespit edildi (Tablo 1).

Araştırmada hemşirelik öğrencilerinin \%59,9'unun hemşirelik eğitiminde örgün eğitimi tercih ettiği, \%66,7'sinin çevrimiçi öğrenmenin hemşirelik mesleğinin kazandırılmasında kullanılabilir bir eğitim-öğretim yöntemi olmadığını düşündüğü, \%52,6'sının hemşirelikte çevrimiçi öğrenmeyi yararlı bulmadığı saptandı. Öğrencilerin çevrimiçi öğrenmeyi yararlı bulmama nedenlerinin sırasıyla; sanal ortamın ders dinleme isteğini azaltması, dikkati dağıtması, sınıf ortamı olmadığı için adapte olamama, internet erişimi kısıtlılığı olduğu tespit edildi. Yararlı olduğunu düşünenlerin ise; \%81,7'sinin gerektiğinde dersin videosunu tekrar izleyerek tekrar yapma ve \%68,9'unun ise mekân esnekliği sağlaması olarak bildirdiği belirlendi. Öğrencilerin \%52,3'ünün hemşirelikte uygulamalı meslek derslerinin çevrimiçi yürütülmesinin, \%47,7'sinin ise hemşirelikte uygulamalı derslerin teorik ile uygulamasının eşgüdümlü gitmemesinin öğrenme verimliliğini azalttığını bildirdiği belirlendi. Öğrencilerin \%42,0'1nın çevrimiçi öğrenmede hemşirelik derslerine hazırlık için ayrılan zamanın ve \%57,4'ünün çevrimiçi öğrenme süresince hemşirelik dersleri ile ilgili makale/kitap/araştırma raporu okuma oranının arttığ $1, \% 40,7$ 'sinin ise çevrimiçi öğrenme süresince hemşirelik derslerine olan ilgisinin değişmediği belirlendi (Tablo 2).

Tablo 1. Hemşirelik öğrencilerinin tanıtıcı özellikleri $(\mathrm{n}=312)$

\begin{tabular}{|c|c|c|}
\hline Özellikler & Sayı (n) & Yüzde (\%) \\
\hline \multicolumn{3}{|l|}{ Yaş } \\
\hline $18-20$ & 120 & 38,5 \\
\hline $21-24$ & 173 & 55,4 \\
\hline 25 yaş ve üzeri & 19 & 6,1 \\
\hline \multicolumn{3}{|l|}{ Cinsiyet } \\
\hline Kadın & 237 & 76,0 \\
\hline Erkek & 75 & 24,0 \\
\hline \multicolumn{3}{|l|}{ Medeni Durum } \\
\hline Evli & 4 & 1,3 \\
\hline Bekâr & 308 & 98,7 \\
\hline \multicolumn{3}{|l|}{ Sinıfi } \\
\hline 1. sinif & 63 & 20,2 \\
\hline 2. sinif & 71 & 22,8 \\
\hline 3. sinif & 84 & 26,9 \\
\hline 4. $\sin 1 f$ & 94 & 30,1 \\
\hline \multicolumn{3}{|l|}{ Yaşadığı yer } \\
\hline İl & 144 & 46,2 \\
\hline İlçe & 106 & 34,0 \\
\hline Köy & 62 & 19,8 \\
\hline \multicolumn{3}{|c|}{ Evinde kendisine ait odası olma } \\
\hline Var & 172 & 55,1 \\
\hline Yok & 140 & 44,9 \\
\hline \multicolumn{3}{|c|}{ Evinde bilgisayarı olma } \\
\hline Var & 175 & 56,1 \\
\hline Yok & 137 & 43,9 \\
\hline \multicolumn{3}{|l|}{ Evinde interneti olma } \\
\hline Var & 207 & 66,3 \\
\hline Yok & 105 & 33,7 \\
\hline \multicolumn{3}{|c|}{ Çevrimiçi derslere katılmak için kullanılan cihaz } \\
\hline $\begin{array}{l}\text { Laptop/Masa üstü } \\
\text { bilgisayar }\end{array}$ & 68 & 21,8 \\
\hline Tablet & 4 & 1,3 \\
\hline Cep telefonu & 240 & 76,9 \\
\hline \multicolumn{3}{|c|}{$\begin{array}{l}\text { Çevrimiçi öğrenme yolu ile eğitimin takip edildiğ } \\
\text { yer }\end{array}$} \\
\hline Ev & 303 & 97,1 \\
\hline $\begin{array}{l}\text { Akraba/komşu/yakın } \\
\text { arkadaş }\end{array}$ & 9 & 2,9 \\
\hline
\end{tabular}


Tablo 2. Hemşirelik öğrencilerinin çevrimiçi öğrenmeye ilişkin görüşleri $(n=312)$

\begin{tabular}{|l|l|l|}
\hline Özellikler & $\boldsymbol{n}$ & \% \\
\hline Hemşirelik eğitiminde tercih edilen öğretim yöntemi & 125 & 40,1 \\
\hline Çevrimiçi & 187 & 59,9 \\
\hline Örgün & & \multicolumn{2}{|l}{} \\
\hline
\end{tabular}

Çevrimiçi öğrenmenin hemşirelik mesleğinin kazandırılmasında kullanılabilir bir eğitim-öğretim yöntemi olduğunu düșünme

Evet uygun

Hayır uygun değil

\begin{tabular}{|l|l|}
\hline 104 & 33,3 \\
\hline 208 & 66,7
\end{tabular}

Hemşirelikte çevrimiçi öğrenmeyi yararlı bulma

Yararl1

Yararlı değil

\begin{tabular}{|l|l|}
\hline 208 & 66,7
\end{tabular}

Hemşirelikte çevrimiçi öğrenmeyi yararlı bulma nedenleri*

\begin{tabular}{|l|l|l}
\hline Daha rahat soru sorma & 68 & 45,9
\end{tabular}

\begin{tabular}{|l|l|l}
\hline Daha çok görsel materyal kullanma & 48 & 32,4
\end{tabular}

\begin{tabular}{|l|l|l}
\hline Gerektiğinde dersin videosunu tekrar izleyerek tekrar yapma & 121 & 81,7
\end{tabular}

\begin{tabular}{|l|l|l}
\hline Sinıf ortamından farklı olarak daha iyi odaklanma & 71 & 47,9
\end{tabular}

\begin{tabular}{|l|l|l|}
\hline Öğrenmeye motive ediyor olma & 46 & 31,0
\end{tabular}

\begin{tabular}{|l|l|l}
\hline Eleştirel düşünme becerisini geliştirme & 44 & 29,7
\end{tabular}

\begin{tabular}{|l|l|l}
\hline Çok yönlü öğrenme olanakları sunma & 64 & 43,2
\end{tabular}

\begin{tabular}{|l|l|l} 
Mekân esnekliği sağlaması & 102 & 68,9
\end{tabular}

Hemşirelikte çevrimiçi öğrenmeyi yararlı bulmama nedenleri *

Sınıf ortamı olmadığı için adapte olamama

Sanal ortamın ders dinleme isteğini azaltma

İnternet erișimi kısıtlılı̆̆ 1

Dikkati dağıtma

\begin{tabular}{|l|l|}
\hline & 68,9 \\
\hline 126 & 76,8 \\
\hline 141 & 85,9 \\
\hline 104 & 63,4 \\
\hline 134 & 81,7 \\
\hline
\end{tabular}

Hemşirelikte uygulamalı meslek derslerinin çevrimiçi yürütülmesinin öğrenme verimliliğini etkilemesi

\begin{tabular}{|l|l|l}
\hline Arttı & 20 & 6,4 \\
\hline Değişmedi & 129 & 41,3 \\
\hline Azaldı & 163 & 52,3
\end{tabular}

Hemşirelikte uygulamalı derslerin teorik ile uygulamasının eşgüdümlü gitmemesinin öğrenme verimliliğini etkilemesi

\begin{tabular}{|l|l|l}
\hline Arttı & 28 & 9,0 \\
\hline Değişmedi & 135 & 43,3 \\
\hline Azald1 & 149 & 47,7
\end{tabular}

Çevrimiçi öğrenmede hemşirelik derslerine hazırlık için ayrılan zaman

\begin{tabular}{|l|l|l}
\hline Arttı & 131 & 42,0 \\
\hline Değişmedi & 96 & 27,2 \\
\hline Azaldı & 85 & 30,8
\end{tabular}

Çevrimiçi öğrenme süresince hemşirelik dersleri ile ilgili makale/kitap/araştırma raporu okuma oranı

\begin{tabular}{|l|l|l|}
\hline Arttı & 179 & 57,4 \\
\hline Değişmedi & 104 & 33,3 \\
\hline Azaldı & 29 & 9,3 \\
\hline Çevrimiçi öğrenme süresince hemşirelik derslerine olan ilgi & \multicolumn{2}{|l}{} \\
\hline Arttı & 75 & 24,0 \\
\hline Değişmedi & 127 & 40,7 \\
\hline Azaldı & 110 & 35,3 \\
\hline
\end{tabular}

*Birden fazla seçenek işaretlenmiştir. 
Araştırmada hemşirelik öğrencilerinin genel kabul, bireysel farkındalık, kullanışlılık ve uygulama etkililiği alt boyut puanlarının sirasiyla $21,61 \pm 5,42,17,49 \pm 6,60$, $9,44 \pm 3,70, \quad 13,97 \pm 3,16$ ve ÇÖTÖ toplam puanın $62,53 \pm 17,22$ olduğu saptandı (Tablo 3).

Tablo 3. Çevrimiçi öğrenme tutum ölçeği (ÇÖTÖ) alt boyut puanları ve toplam puanı $(\mathrm{n}=312)$

\begin{tabular}{|l|l|l|}
\hline Alt Boyutlar & $\overline{\boldsymbol{x}} \pm \boldsymbol{s s}$ & $\begin{array}{l}\text { M(Min- } \\
\text { Max })\end{array}$ \\
\hline Genel Kabul & $21,61 \pm 5,42$ & $22(7-35)$ \\
\hline Bireysel Farkındalık & $17,49 \pm 6,60$ & $17(6-30)$ \\
\hline $\begin{array}{l}\text { Kullanışlılık (Zaman- } \\
\text { Emek-Maliyet) }\end{array}$ & $9,44 \pm 3,70$ & $10(3-15)$ \\
\hline $\begin{array}{l}\text { Uygulama Etkililiği } \\
\text { (Etkin katılım) }\end{array}$ & $13,97 \pm 3,16$ & $14(4-20)$ \\
\hline Toplam & $62,53 \pm 17,22$ & $63(20-100)$ \\
\hline
\end{tabular}

$\bar{x}$ : Ortalama, ss: Standart sapma, M: Ortanca, Min: En küçük değer, Max: En büyük değer

Araştırmada hemşirelik öğrencilerinden yaşı 25 ve üzeri olanların genel kabul, kullanışlılık alt boyut puanları ile ÇÖTÖ toplam puanının daha yüksek olduğu tespit edildi $(p<0,05)$. Erkek öğrencilerin genel kabul, bireysel farkındalık alt boyut puanlarının kız öğrencilerden daha yüksek olduğu belirlendi $(p<0,05)$. Dördüncü sınıf ögrencilerinin genel kabul, bireysel farkındalık alt boyut puanlarının daha düşük olduğu saptandı $(p<0,05)$. Öğrencilerin yaşadığı yere göre tüm alt boyut puanları ve ÇÖTÖ toplam puanı arasında bir fark bulunmadı $(p>0,05)$. Evinde bilgisayarı olan öğrencilerin genel kabul, bireysel farkındalık, kullanışlılık alt boyut puanları ve ÇÖTÖ toplam puanının daha yüksek olduğu belirlendi $(p<0,05)$. Evinde interneti olanların tüm alt boyut puanları ve ÇÖTÖ toplam puanının yüksek olduğu tespit edildi $(p<0,05)$. Çevrimiçi derslere katılmak için tablet kullanan öğrencilerin genel kabul alt boyutu puanı daha yüksek bulunurken $(p<0,05)$; bireysel farkındalık, kullanışlılık, uygulama etkililiği alt boyut puanları ve ÇÖTÖ toplam puanı arasında fark bulunmadı $(p>0,05)$. Evinde kendisine ait odası olma ve çevrimiçi öğrenme yolu ile eğitimin takip edildiği yer ile tüm alt boyut puanları ve ÇÖTÖ toplam puanı arasında fark bulunmadı $(p>0,05)$ (Tablo 4).

Araştırmada çevrimiçi öğrenmenin hemşirelik mesleğinin kazandırılmasında kullanılabilir bir eğitim öğretim yöntemi olduğunu düşünen ve hemşirelikte çevrimiçi öğrenmeyi yararlı bulan öğrencilerin tüm alt boyut puanları ve ÇÖTÖ toplam puanının daha yüksek olduğu saptandı $(p<0,001)$. Hemşirelikte uygulamalı meslek derslerinin çevrimiçi yürütülmesinin ve hemşirelikte uygulamalı derslerin teorik ile uygulamasının eşgüdümlü gitmemesinin öğrenme verimliliğini artırdığını düşünen öğrencilerin tüm alt boyut puanları ve ÇÖTÖ toplam puanının daha yüksek olduğu belirlendi $(p<0,001)$. Çevrimiçi öğrenme süresince hemşirelik derslerine olan ilgi ile hemşirelik dersleri ile ilgili makale/kitap/araştırma raporu okuma oranının arttığını ve çevrimiçi öğrenmede hemşirelik derslerine hazırlık için ayrılan zamanın değişmediği yönünde görüş bildiren öğrencilerin tüm alt boyut puanları ve ÇÖTÖ toplam puanının daha yüksek olduğu tespit edildi $(p<0,05)$ (Tablo 5).

\section{TARTISMA}

$\mathrm{Bu}$ araştırma COVID-19 pandemisi sürecinde hemşirelik öğrencilerinin çevrimiçi öğrenmeye yönelik görüş ve tutumlarını belirlemek amacıyla yapılmış olup elde edilen bulgular literatür eşliğinde tartışılmıştır. $\mathrm{Bu}$ araştırmada hemşirelik öğrencilerinin tamamına yakınının çevrimiçi öğrenme yolu ile eğitimini evinden takip ettiği, yarısından fazlasının evinde bilgisayarı, interneti ve kendisine ait odası olduğu ve çoğunluğunun cep telefonu ile derslere katıldığ 1 saptand 1 (Tablo 1). Subedi ve arkadaşlarının (25) COVID-19 pandemisi sürecinde eöğrenmenin etkisini değerlendirdikleri araştırmasında hemşirelik öğrencilerinin yarısından fazlasının evinde internet erişimi olduğu ve çevrimiçi sınıflar için cep telefonu kullandığı belirlenmiştir. $\mathrm{Bu}$ bulguların aksine Çelik Eren ve arkadaşları (26), Keskin Kızıltepe ve Kurtgöz (27) tarafindan yapılan araştırmalarda COVID19 pandemisi sürecinde uzaktan eğitim için hemşirelik öğrencilerinin yarısından fazlasının bilgisayar kullandığı saptanmıştır. Hemşirelik öğrencilerinin cep telefonu ile dersleri takip etmesi bilgisayar ile kıyaslandığında görüş alanının daha küçük olması, mesaj gelmesi, aranma gibi nedenlerle dikkatin dağılması ve ders dinlemenin bölünmesine yol açabileceği düşünülmüştür.

$\mathrm{Bu}$ araştırmada hemşirelik öğrencilerinin yarısından fazlasının hemşirelik eğitiminde tercih ettiği öğretim yönteminin örgün eğitim olduğu, çevrimiçi öğrenmenin hemşirelik mesleğinin kazandırılmasında kullanılabilir bir eğitim-öğretim yöntemi olmadığını düşündüğü tespit edildi (Tablo 2). Hemşirelik eğitiminde uzaktan eğitimi literatür bilgileri doğrultusunda ele alan bir derlemede uzaktan eğitimin hemşirelik eğitiminde tek başına kullanılabilecek bir yöntem olmaktan ziyade örgün eğitimi destekleyici bir yöntem olarak değerlendirilmesi gerektiği vurgulanmıştır (28). Atasoy ve Sütütemiz'in (29) hemşirelik son sınıf öğrencileri ile yaptıkları araştırmada öğrencilerin yüksek ortalama ile hemşirelik lisans eğitiminin örgün eğitim olması gerektiğine yönelik görüş bildirdiği saptanmıştır. Durgun ve arkadaşlarının (30) yapmış olduğu araştırmada COVID-19 pandemisi sürecinde hemşirelik öğrencilerinin uzaktan eğitime yönelik görüşler ölçeği puan ortalamasının orta düzeyde olumlu olduğu bildirilmiştir. $\mathrm{Bu}$ doğrultuda hemşirelik eğitiminde çevrimiçi öğrenme ve örgün eğitim sonuçlarının kıyaslandığ $\breve{1}_{1}$ araştırmaların yapılması gerektiği düşünülmüştür.

$\mathrm{Bu}$ araştırmada hemşirelik öğrencilerinin hemşirelikte çevrimiçi öğrenmeyi yararlı bulma nedenlerinin gerektiğinde dersin videosunu tekrar izleyerek tekrar yapma ve mekân esnekliği sağlaması olduğu saptandı (Tablo 2). Şenyuva'nın (22) yapmış olduğu araştırmada hemşirelik öğrencilerinin uzaktan eğitimin yararlarına ilişkin görüşleri doğrultusunda oluşturulan temalar arasında bireysel öğrenmeyi desteklediği, zaman ve mekân sınırlılığını en aza indirdiği, ileri teknoloji kullanma firsatı verdiği ve eğitimin sürekli, ekonomik ve nitelikli olmasını desteklediği bildirilmiştir. Kahyaoğlu Süt ve Küçükkaya'nın (21) yapmış olduğu araştırmada, hemşirelik öğrencilerinin uzaktan eğitimin olumlu yönlerine ilişkin görüşleri arasında bilginin elde edilmesinde ekonomik olacağı, mezuniyetten sonra aile 
Tablo 4. Hemşirelik Öğrencilerinin Bazı Tanıtıcı Özelliklerine Göre ÇÖTÖ Alt Boyut Puanları ve Toplam Puanın Kıyaslanması

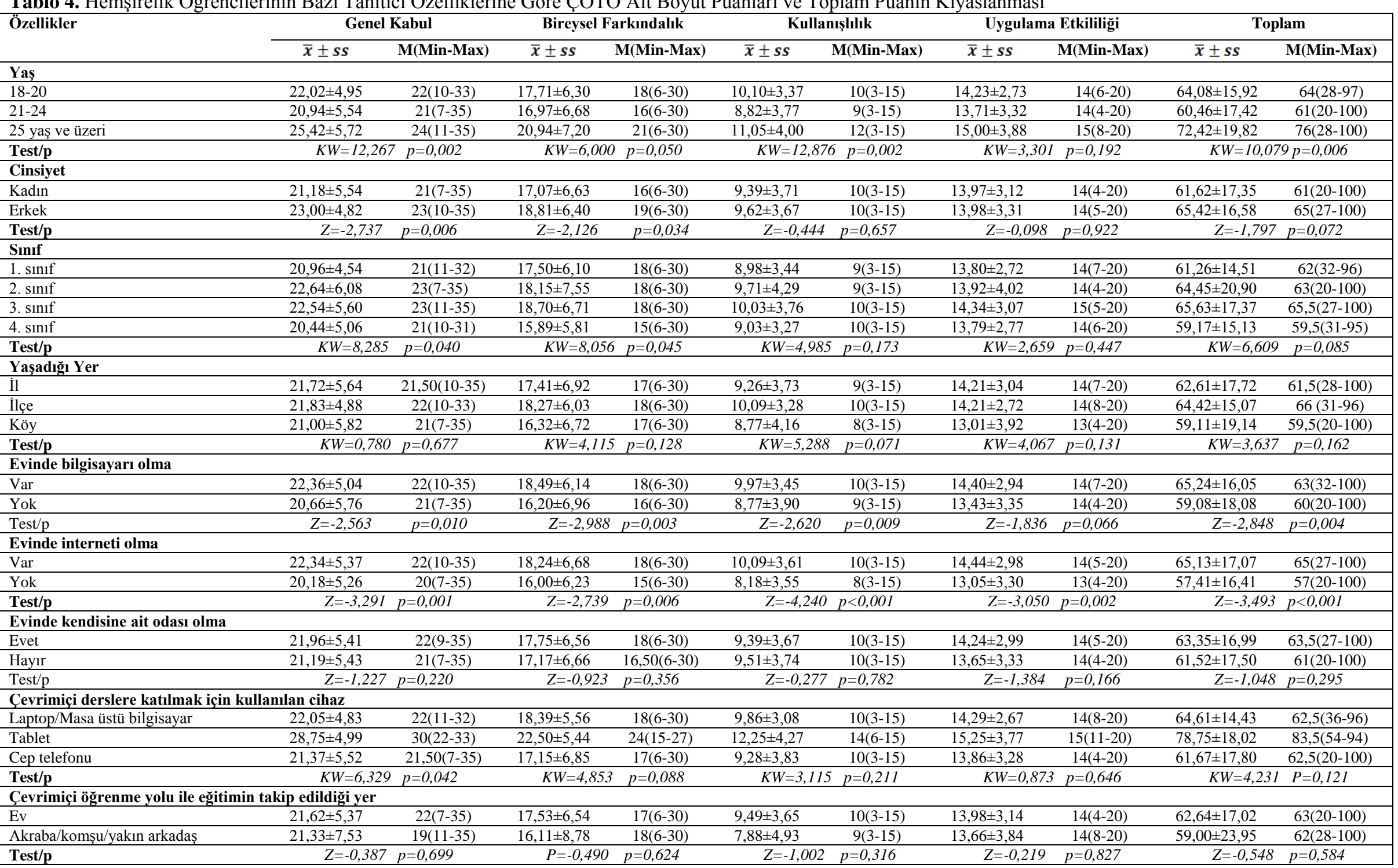

$\bar{x}$ : Ortalama, ss: Standart sapma, $M$ : Ortanca, Min: En küçük değer, Max: En büyük değer, $K W$ : Kruskal-Wallis testi, Z: Mann-Whitney $U$ test 
Tablo 5. Hemşirelik Öğrencilerinin Çevrimiçi Öğrenmeye İlişkin Görüşlerine Göre ÇÖTÖ Alt Boyut Puanları ve Toplam Puanın Kıyaslanması

\begin{tabular}{|c|c|c|c|c|c|c|c|c|c|c|}
\hline \multirow[t]{2}{*}{ Özellikler } & \multicolumn{2}{|c|}{ Genel Kabul } & \multicolumn{2}{|c|}{ Bireysel Farkındalık } & \multicolumn{2}{|c|}{ Kullanışılık } & \multicolumn{2}{|c|}{ Uygulama Etkililiği } & \multicolumn{2}{|c|}{ Toplam } \\
\hline & $\bar{x} \pm s s$ & M(Min-Max) & $\bar{x} \pm s s$ & M(Min-Max) & $\bar{x} \pm s s$ & M(Min-Max) & $\bar{x} \pm s s$ & M(Min-Max) & $\bar{x} \pm s s$ & M(Min-Max) \\
\hline \multicolumn{11}{|c|}{ Çevrimiçi öğrenmenin hemşirelik mesleğinin kazandırılmasında kullanılabilir bir eğitim öğretim yöntemi olduğunu düşünme } \\
\hline Evet & $25,91 \pm 4,48$ & $26(14-35)$ & $23,26 \pm 5,18$ & $24(10-30)$ & $12,26 \pm 2,55$ & $12(6-15)$ & $16,03 \pm 2,63$ & $16(8-20)$ & $77,49 \pm 13,50$ & $77(45-100)$ \\
\hline Hayır & $19,47 \pm 4,51$ & $20(7-35)$ & $14,60 \pm 5,20$ & $14(6-29)$ & $8,03 \pm 3,36$ & $8(3-15)$ & $12,94 \pm 2,89$ & $13(4-20)$ & $55,05 \pm 13,65$ & $55,5(20-95)$ \\
\hline Test $/ \mathrm{p}$ & $Z=-9,96$ & $P<0,001$ & $Z=-10,80$ & $P<0,001$ & $Z=-9,55$ & $P<0,001$ & $Z=-8,25$ & $P<0,001$ & $\mathrm{Z}=-10,80$ & $P<0,001$ \\
\hline \multicolumn{11}{|c|}{ Hemşirelikte çevrimiçi öğrenmeyi yararlı bulma } \\
\hline Evet & $25,38 \pm 4,07$ & $25(14-35)$ & $22,36 \pm 4,95$ & $22(10-30)$ & $12,25 \pm 2,26$ & $12(6-15)$ & $15,79 \pm 2,55$ & $16(9-20)$ & $75,80 \pm 12,20$ & $74,5(45-100)$ \\
\hline Hayır & $18,21 \pm 4,10$ & $19(7-26)$ & $13,09 \pm 4,49$ & $13(6-26)$ & $6,91 \pm 2,80$ & $7(3-13)$ & $12,33 \pm 2,73$ & $13(4-20)$ & $50,56 \pm 11,29$ & $51(20-72)$ \\
\hline Test $/ \mathrm{p}$ & $Z=-12,04$ & $P<0,001$ & $Z=-12,66$ & $P<0,001$ & $Z=-12,96$ & $P<0,001$ & $Z=-9,49$ & $P<0,001$ & $Z=-13,37$ & $P<0,001$ \\
\hline \multicolumn{11}{|c|}{ Hemşirelikte uygulamalı meslek derslerinin çevrimiçi yürütülmesinin öğrenme verimliliğini etkilemesi } \\
\hline Artt1 & $29,10 \pm 4,44$ & $31(17-35)$ & $26,53 \pm 4,63$ & $28(11-30)$ & $13,89 \pm 2,13$ & $15(7-15)$ & $17,96 \pm 2,00$ & $18(12-20)$ & $87,50 \pm 12,20$ & $92,5(50-100)$ \\
\hline Değişmedi & $23,53 \pm 3,85$ & $23(12-35)$ & $19,99 \pm 5,18$ & $20(6-30)$ & $10,92 \pm 2,72$ & $12(3-15)$ & $14,77 \pm 2,43$ & $15(8-20)$ & $69,22 \pm 12,18$ & $69(40-100)$ \\
\hline Azald 1 & $18,47 \pm 4,58$ & $19(7-32)$ & $13,52 \pm 5,14$ & 14(6-29) & $7,27 \pm 3,27$ & $7(3-15)$ & $12,51 \pm 3,02$ & $13(4-20)$ & $51,78 \pm 13,66$ & $51(20-87)$ \\
\hline Test/p & $K W=115,67$ & $P<0,001$ & $K W=122,48$ & $P<0,001$ & $K W=113,03$ & $P<0,001$ & $K W=83,15$ & $P<0,001$ & $K W=132,16$ & $P<0,001$ \\
\hline \multicolumn{11}{|c|}{ Hemşirelikte uygulamalı derslerin teorik ile uygulamasının eşgüdümlü gitmemesinin öğrenme verimliliğini etkilemesi } \\
\hline Artt1 & $27,80 \pm 5,42$ & $29(17-35)$ & $24,70 \pm 6,36$ & $27(11-30)$ & $12,65 \pm 3,18$ & $15(6-15)$ & $17,35 \pm 3,09$ & $19(10-20)$ & $82,50 \pm 17,16$ & $91(49-100)$ \\
\hline Değişmedi & $23,54 \pm 4,69$ & $24(11-35)$ & $20,33 \pm 5,57$ & $21(6-30)$ & $10,79 \pm 3,17$ & $11(3-15)$ & $14,80 \pm 2,61$ & $15(8-20)$ & $69,48 \pm 14,43$ & $70(31-100)$ \\
\hline Azald 1 & $19,33 \pm 4,77$ & $19(7-35)$ & $14,35 \pm 5,63$ & $14(6-29)$ & $7,98 \pm 3,50$ & $8(3-15)$ & $12,90 \pm 3,09$ & $13(4-20)$ & $54,58 \pm 14,80$ & $53(20-95)$ \\
\hline Test/p & $K W=70,63$ & $P<0,001$ & $\mathrm{KW}=84,47$ & $P<0,001$ & $K W=55,35$ & $5 P<0,001$ & $K W=43,59$ & $P<0,001$ & $\mathrm{KW}=78,19$ & $P<0,001$ \\
\hline \multicolumn{11}{|c|}{ Çevrimiçi öğrenmede hemşirelik derslerine hazırlık için ayrılan zaman } \\
\hline Artt1 & $21,57 \pm 5,92$ & $21(9-35)$ & $17,67 \pm 7,01$ & $17(6-30)$ & $9,29 \pm 4,11$ & $9(3-15)$ & $14,28 \pm 3,31$ & $14(8-20)$ & $62,82 \pm 18,63$ & $62(27-100)$ \\
\hline Değişmedi & $23,32 \pm 4,30$ & $23(11-35)$ & $19,61 \pm 5,77$ & $19,5(6-30)$ & $10,87 \pm 2,85$ & $11(3-15)$ & $14,41 \pm 2,69$ & $14(8-20)$ & $68,22 \pm 14,20$ & $68(28-100)$ \\
\hline Azald 1 & $19,76 \pm 5,19$ & $19(7-32)$ & $14,81 \pm 5,95$ & $14(6-29)$ & $8,07 \pm 3,31$ & $8(3-15)$ & $13,01 \pm 3,23$ & $13(4-20)$ & $55,65 \pm 15,73$ & $55(20-93)$ \\
\hline Test/p & $K W=21,53$ & $P<0,001$ & $K W=23,98$ & $P \quad P<0,001$ & $K W=26,65$ & $5 \quad P<0,001$ & $K W=8,69$ & $P=0,013$ & $K W=25,12$ & $P<0,001$ \\
\hline \multicolumn{11}{|c|}{ Çevrimiçi öğrenme süresince hemşirelik dersleri ile ilgili makale/kitap/araştırma raporu okuma oranı } \\
\hline Artt1 & $22,48 \pm 5,38$ & $23(9-35)$ & $18,66 \pm 6,62$ & $19(6-30)$ & $10,20 \pm 3,68$ & $11(3-15)$ & $14,60 \pm 3,01$ & $15(8-20)$ & $65,94 \pm 17,01$ & $66(27-100)$ \\
\hline Değişmedi & $21,48 \pm 5,14$ & $22(10-35)$ & $16,96 \pm 6,15$ & $16,5(6-30)$ & $9,14 \pm 3,31$ & $9(3-15)$ & $13,53 \pm 2,87$ & $13(6-20)$ & $61,12 \pm 15,86$ & $61(28-100)$ \\
\hline Azald 1 & $16,79 \pm 4,12$ & $16(7-28)$ & $12,13 \pm 5,26$ & $13(6-25)$ & $5,89 \pm 2,90$ & $5(3-13)$ & $11,68 \pm 3,76$ & $12(4-17)$ & $46,51 \pm 13,47$ & $46(20-77)$ \\
\hline Tesdt/p & $K W=29,41$ & $P<0,001$ & $K W=25,30$ & $P<0,001$ & $K W=33,49$ & $9 P<0,001$ & $K W=20,84$ & $P<0,001$ & $\mathrm{KW}=31,88$ & $P<0,001$ \\
\hline \multicolumn{11}{|c|}{ Çevrimiçi öğrenme süresince hemşirelik derslerine olan ilgi } \\
\hline Artt1 & $25,68 \pm 4,89$ & $26(11-35)$ & $21,77 \pm 6,34$ & $22(6-30)$ & $11,94 \pm 3,28$ & $12(3-15)$ & $15,97 \pm 2,80$ & $16(8-20)$ & $75,37 \pm 16,08$ & $76(28-100)$ \\
\hline Değişmedi & $22,15 \pm 4,49$ & $22(10-35)$ & $18,63 \pm 5,59$ & $18(6-30)$ & $10,33 \pm 3,02$ & $11(3-15)$ & $14,22 \pm 2,74$ & $14(7-20)$ & $65,35 \pm 14,14$ & $65(28-100)$ \\
\hline Azald1 & $18,22 \pm 4,60$ & $18(7-32)$ & $13,24 \pm 5,36$ & $13(6-29)$ & $6,71 \pm 2,90$ & $7(3-15)$ & $12,33 \pm 2,99$ & $12(4-20)$ & $50,52 \pm 13,08$ & $49(20-87)$ \\
\hline Test $/ \mathrm{p}$ & $K W=87,85$ & $P<0,001$ & $K W=86,07$ & $P<0,001$ & $K W=102,17$ & $7 \quad P<0,001$ & $K W=60,52$ & $P<0,001$ & $K W=102,07$ & $7 P<0,001$ \\
\hline
\end{tabular}

$\bar{x}$ : Ortalama, ss: Standart sapma, M: Ortanca, Min: En küçük değer, Max: En büyük değer, KW: Kruskal-Wallis testi, Z: Mann-Whitney $U$ testi 
hayatını sürdürmeyi kolaylaştıracağı, internet yoluyla iş güncelleştirilebileceği olarak sıralanmıştır. Keskin Kızıltepe ve Kurtgöz'ün (27) yapmış olduğu araştırmada ise hemşirelik öğrencilerinin hastanede staja çıkmadıkları ve sınıf ortamında bulunmadıkları için COVID-19 bulaşma riskinin azalmış olması nedeni ile kendilerini güvende hissetmeleri ve derslerin teorik anlatımının daha iyi ilerlediğini düşünmeleri uzaktan eğitimin olumlu özellikleri arasında bildirilmiştir. Buna karşın hemşirelik öğrencilerinin çoğunluğunun hemşirelikte çevrimiçi öğrenmeyi yararlı bulmama nedenlerinin sanal ortamın ders dinleme isteğini azaltması, dikkati dağıtması, sınıf ortamı olmadığ 1 için adapte olamama, internet erişiminin kısıtlı olmasının olduğu belirlendi (Tablo 2). Kürtüncü ve Kurt'un (31) araştırmasında COVID-19 pandemisi sürecinde hemşirelik öğrencilerinin uzaktan eğitim konusunda yaşadığı sorunların üniversitenin uzaktan eğitim alt yapısındaki sorunlar, eğitimin yüz yüze olmaması, imkân kısıtlılığı, pandeminin getirdiği duygudurum ve sınav kaygısı olarak temalandırılmıştır. Bununla birlikte Kaya ve Akın Işık'ın (32) yapmış olduğu araştırmada COVID-19 pandemisinde hemşirelik öğrencileri tarafından uzaktan eğitimde yaşanan sorunların nedenleri arasında bilgisayar ve internetin olmaması ile ev ortamından kaynaklanan sorunlar olduğu bildirilmiştir. Çevrimiçi öğrenmenin olumlu ve olumsuz yönleri göz önünde bulundurularak hemşirelik eğitiminde örgün eğitimi destekleyici bir eğitim öğretim yöntemi olarak kullanılabileceği düşünülmüştür.

$\mathrm{Bu}$ araştırmada hemşirelik öğrencilerinin yarısından fazlasının hemşirelikte uygulamalı meslek derslerinin çevrimiçi yürütülmesinin ve yarısına yakınının hemşirelikte uygulamalı derslerin teorik ile uygulamasının eşgüdümlü gitmemesinin öğrenme verimliliğini azalttığını düşündüğü tespit edildi (Tablo 2). Nitekim Özbay ve Çınar'ın (33) araştırmasında da hemşirelik öğrencilerinin çoğunluğunun uzaktan eğitimin hemşirelik alanında uygulamaya dayalı yetkinlikler kazandırmada yeterli olmadığını ve bu alanda önemli bir yere sahip olan laboratuvar ve klinik uygulamalarda eksikliklere sebep olabileceğini belirttiği bildirilmiştir. Kahyaoğlu Süt ve Küçükkaya'nın (21) yaptığı araştırmada hemşirelik öğrencilerinin çoğunluğunun hemşirelikte uzaktan eğitimi onaylamadıklarını, hemşirelikteki tüm programların uzaktan eğitim ile verilemeyeceğini, uygulama ağırlıklı olan hemşirelik mesleğinde önemli bir yeri olan laboratuvar ve klinik uygulamalarda eksikliklere neden olacağını düşündükleri belirlenmiştir. $\mathrm{Bu}$ bulguların aksine Şenyuva ve arkadaşlarının (34) hemşirelik öğrencilerinin çoğunluğunun web tabanlı hasta eğitimi dersinin yöntemine, tasarımına ve ders kazanımlarına ilişkin olumlu görüşlere sahip olduğu bildirilmiştir.

$\mathrm{Bu}$ araştırmada hemşirelik öğrencilerinin yarısına yakınının çevrimiçi öğrenmede hemşirelik derslerine hazırlık için ayrılan zamanın ve yarısından fazlasının çevrimiçi öğrenme süresince hemşirelik dersleri ile ilgili makale/kitap/araştırma raporu okuma oranının arttığ belirlenirken; yarısına yakınının çevrimiçi öğrenme süresince hemşirelik derslerine olan ilgisinin değişmediği tespit edildi (Tablo 2). Yapılan bir randomize kontrollü araştırmada, karma öğrenme yaklaşımıyla klinik süpervizör becerileri eğitimi alan hemşirelik birliğine olanak sağlaması ve bilgilerin sürekli öğrencilerinin motivasyon, tutum, bilgi ve memnuniyet açısından çevrimiçi öğrenme grubuna göre daha yüksek puan aldığı bildirilmiştir (35).

$\mathrm{Bu}$ araştırmada hemşirelik öğrencilerinin ÇÖTÖ toplam puanından elde edilen sonuca göre çevrimiçi öğrenmeye yönelik tutumlarının orta derecede olduğu düşünülmüştür (Tablo 3). Gaur ve arkadaşlarının (36) yapmış olduğu araştırmada COVID-19 pandemisi sürecinde Hindistan'daki karantina döneminde hemşirelik öğrencilerinin çoğunluğunun çevrimiçi sınıflara karş1 olumsuz bir tutum gösterdiği bildirilmiştir. Thapa ve arkadaşlarının (37) yapmış olduğu araştırmada ise COVID-19 pandemisi sürecinde e-öğrenme uygulamasına ilişkin hemşirelik öğrencilerinin yarısından fazlasının olumlu bir tutuma sahip olduğu belirlenmiştir. $\mathrm{Bu}$ araştırmada yaşı yirmi beş ve üzeri olan öğrencilerin genel kabul, kullanışlılık alt boyut puanları ile ÇÖTÖ toplam puanının daha yüksek olduğu belirlendi. Erkek öğrencilerin genel kabul, bireysel farkındalık alt boyut puanlarının kız öğrencilerden daha yüksek olduğu saptandı. İkinci sınıf öğrencilerinin genel kabul, üçüncü sınıf öğrencilerinin ise bireysel farkındalık alt boyut puanının daha yüksek olduğu belirlendi (Tablo 4). Akimanimpaye ve Fakude'nin (38) hemşirelik öğrencilerinin e-öğrenmeye ilişkin tutumlarını belirlemek amacıyla yaptıkları araştırmada e-öğrenmeye karşı memnuniyette algılanan kullanım kolaylığı, cinsiyet ve sınıfın etkili olduğu belirlenmiştir.

$\mathrm{Bu}$ araştırmada evinde bilgisayarı olan hemşirelik öğrencilerinin genel kabul, bireysel farkındalı, kullanışlılık alt boyut puanlarının ve ÇÖTÖ toplam puanının; interneti olanların tüm alt boyut puanları ve ÇÖTÖ toplam puanının; çevrimiçi derslere katılmak için tablet kullananların genel kabul alt boyut puanının daha yüksek olduğu belirlendi (Tablo 4). Ali ve arkadaşlarının (39) hemşirelik öğrencilerinin e-öğrenmeye karş1 tutumlarını değerlendirdikleri araştırmada öğrencilerin eöğrenmeyi benimsemeye hazır oldukları ancak teknik destekle ilgili zorlukları ve teknolojiyi kullanmanın stresini bir engel olarak gördükleri bildirilmiştir. $\mathrm{Bu}$ sonuçlar çevrimiçi öğrenme ile ilgili teknik alt yapısı olan hemşirelik öğrencilerinin tutumlarının daha olumlu olduğu şeklinde yorumlanabilir.

$\mathrm{Bu}$ araştırmada ÇÖTÖ alt boyut puanları ve toplam puanı yüksek olan hemşirelik öğrencilerinin düşük olanlara göre hemşirelik eğitiminde çevrimiçi öğrenmeye ilişkin olumlu görüş (hemşirelik mesleğinin kazandırılmasında kullanılabilir bir eğitim öğretim yöntemi olduğunu düşünme, çevrimiçi öğrenmeyi yararlı bulma, uygulamalı meslek derslerinin çevrimiçi yürütülmesinin ve uygulamalı derslerin teorikleri ile uygulamasının eşgüdümlü gitmemesinin öğrenme verimliliğini artırması, hemşirelik dersleri ile ilgili makale/kitap/araştırma raporu okuma oranının ve hemşirelik derslerine olan ilginin artmas1) bildirdiği belirlendi (Tablo 5). Maurya ve arkadaşlarının (40) yapmış olduğu araştırmada COVID19 pandemisi karantina sürecinde hemşirelik öğrencilerinin çevrimiçi öğrenmeyle ilgili yeterli kabul edilebilirlik, olumlu tutumlar ve daha yüksek memnuniyet seviyeleri gösterdiği belirtilmiştir. Bu doğrultuda hemşirelik öğrencilerinin çevrimiçi öğrenmeye ilişkin olumsuz tutum geliştirmelerine neden 
olan faktörlerin detaylı olarak belirlenmesi ve bunların iyileştirilmesine yönelik araştırmaların yapılması gerektiği düşünülmüştür.

\section{SONUÇ}

$\mathrm{Bu}$ araştırmada hemşirelik öğrencilerinin çoğunluğunun hemşirelik eğitiminde çevrimiçi öğrenmeyi tercih etmediği saptandı. Öğrencilerin çoğunluğunun çevrimiçi dersleri cep telefonu ile takip ettiği belirlendi. Yaşı yirmi beş ve üzeri olan öğrencilerin genel kabul, kullanışlılık alt boyut puanları ile ÇÖTÖ toplam puanının daha yüksek olduğu tespit edildi. Erkek öğrencilerin genel kabul, bireysel farkındalı alt boyut puanlarının kız öğrencilerden daha yüksek olduğu saptandı. ÇÖTÖ alt boyut puanları ve toplam puanı yüksek olan öğrencilerin düşük olan öğrencilere göre hemşirelik eğitiminde çevrimiçi öğrenmeye ilişkin olumlu görüş bildirdikleri saptand1.

\section{ÖNERILLER}

Pandemi sürecinde hemşirelik eğitiminde çevrimiçi öğrenme yönteminin kullanımının devam etmesi durumunda alt yapı eksiklikleri ve teknik sorunların giderilmesi için ögrrencilerin desteklenmesi önerilebilir. Buna ek olarak video, sanal simülasyon uygulamaları ve kanıt temelli senaryo tasarımları ile eğitimin içeriğinin zenginleştirilerek hemşirelik uygulamalarının çevrimiçi öğrenme ortamında da eşgüdümlü yapılmasının sağlanması önerilebilir. Ayrıca araştırma bulguları doğrultusunda örgün eğitime geçiş yapılması durumunda çevrimiçi öğrenme yöntemlerinin örgün eğitimi destekleyici bir eğitim öğretim yöntemi olarak kullanılması önerilebilir.

Yazarların Katkıları: Y.Ş.; Tasarım Y.Ş., A.Ş.T., R.H.A.; Veri Toplama ve/veya İşleme Y.Ş., A.Ş.T.; Analiz ve/veya Yorum Y.Ş., A.Ş.T., R.H.A.; Literatür Taraması Y.Ş., A.Ş.T., R.H.A.; Makale Yazımı Y.Ş., A.Ş.T.; Eleştirel İnceleme Y.Ş., A.Ş.T., R.H.A.

\section{KAYNAKLAR}

1. Nar MŞ. COVID-19 salgını ve dönüşümün etkisi: Şimdi ve sonrası. İMGELEM. 2020; 4 (7): 363-82.

2. Can E. Coronavirüs (Covid-19) pandemisi ve pedagojik yansımaları: Türkiye'de açık ve uzaktan eğitim uygulamaları. Açıköğretim Uygulamaları ve Araştırmaları Dergisi. 2020; 6(2): 11-53.

3. Pokhrel S, Chhetri R. A Literature review on impact of COVID-19 pandemic on teaching and learning. Higher Education for the Future. 2021;8(1):133-41. https://doi.org/10.1177/2347631120983481

4. Türk Tabipleri Birliği (TTB). COVID-19 pandemisi iki aylık değerlendirme raporu [Internet]. Türk Tabipleri Birliği COVID-19 Danışma ve İzleme Kurulu; 14 Mayıs 2020 [Erişim tarihi:14.10.2020]. Erişim adresi: https://www.ttb.org.tr/userfiles/files/covid19-rapor.pdf.

5. United Nations Educational, Scientific and Cultural Organization (UNESCO). UN Secretary-General warns of education catastrophe, pointing to UNESCO estimate of 24 million learners at risk of dropping out. [Internet]. UNESCO; [Updated: 06.08.2020; Cited:14.10.2020]. Available from: https://en.unesco.org/news/secretary- general-warns-education-catastrophe-pointing-unescoestimate-24-million-learners-0.

6. Telli Yamamoto G, Altun D. Coronavirüs ve çevrimiçi (online) eğitimin önlenemeyen yükselişi. Üniversite Araştırmaları Dergisi. 2020;3(1):25-34. https://doi.org/ 10.26701/uad.711110

7. Can E. Açık ve uzaktan yükseköğretim mezunları üzerine bir değerlendirme. Açıköğretim Uygulamaları ve Araştırmaları Dergisi. 2019;5(3):81-105.

8. Seaman JE, Allen IE, Seaman J. Grade increase: Tracking distance education in The United States [Internet]. Babson Survey Research Group; 2018 [Cited:14.10.2020]. Available from: https://onlinelearningsurvey.com/reports/gradeincrease.p df.

9. Dhull I, Sakshi MS. Online learning. International Education \& Research Journal. 2017; 3(8): 32-4.

10. Atatürk Üniversitesi Uzaktan Eğitim Uygulama ve Araştırma Merkezi (ATAUZEM). [İnternet]. [Erişim tarihi: 17.10.2020]. Erişim adresi: https://atauzem.atauni.edu.tr/programlar/hemsireliklisans-tamamlama.

11. Boz Yüksekdağ B. Hemşirelik eğitiminde bilgisayar teknolojisinin kullanımı. Açık öğretim Uygulamaları ve Araştırmaları Dergisi. 2015; 1(1): 103-18.

12. Hsieh HY, Hsu YY, Ko NY, Yen M. Nursing education strategies during the COVID-19 epidemic. Hu Li Za Zhi. 2020; 67(3): 96-101. https://doi.org/ 10.6224/JN.202006_67(3).13

13. Tomietto M, Comparcini D, Simonetti V, Cicolini G. Nursing education: challenges and perspectives in a COVID-19 age. Prof Inferm. 2020; 73(3): 131-2. https://doi.org/10.7429/pi.2020.733131

14. Seven M, Abban S. COVID-19 pandemi sürecinde uzaktan hemşirelik eğitimi: Uluslararası deneyim. İzmir Kâtip Çelebi Üniversitesi Sağlık Bilimleri Fakültesi Dergisi. 2021; 6(1): 29-32.

15. Kozan EH, Çolak M, Demirhan BS. Distance education in the COVID-19 pandemic: reflections on nursing education. J Educ Res Nurs. 2021; 18(Supp. 1): 60-4. https://doi.org/10.5152/jern.2021.79084

16. Şanlı D, Uyanık G, Ünsal Avdal E. COVID-19 pandemi sürecinde dünyada hemşirelik eğitimi. İzmir Kâtip Çelebi Üniversitesi Sağlık Bilimleri Fakültesi Dergisi. 2021; 6(1): 55-63.

17. American Association of Colleges of Nursing (AACN). Position Statements: Alliance for nursing accreditation statement on distance education policies [Internet]. January, 2003. [Cited:17.10.2020]. Available from: https://www.aacnnursing.org/NewsInformation/Position-Statements-White-Papers/DistanceEducation.

18. Usta İ, Uysal Ö, Okur MR. Çevrimiçi öğrenme tutum ölçeği: Geliştirilmesi, geçerliği ve güvenirliği. Uluslararası Sosyal Araştırmalar Dergisi. 2016; 9(43): 2215-22.

19. Bayram M, Peker AT, Aka ST, Vural M. Üniversite öğrencilerinin uzaktan eğitim dersine karşı tutumlarının incelenmesi. Gaziantep Üniversitesi Spor Bilimleri Dergisi. 2019; 4(3): $\quad 330-45$. https://doi.org/10.31680/gaunjss.586113

20. Çetintaş Öner S, Çelik G, Bay H, Yeşil Y, Çeber Turfan E. Ebelik bölümü uzaktan eğitim öğrencilerinin e- 
öğrenme için hazırbulunuşluk durumlarının değerlendirilmesi. Medical Sciences (NWSAMS). 2018; 13(1): 10-8. https://doi.org/10.12739/NWSA.2018.13.1.1B0046

21. Kahyaoğlu Süt H, Küçükkaya B. Hemşirelik bölümü öğrencilerinin uzaktan eğitime ilişkin görüşleri. Hemşirelikte Eğitim ve Araştırma Dergisi. 2016; 13(3): 235-43. https://doi.org/10.5222/HEAD.2016.235

22. Şenyuva E. Nursing student's view about distance education. International Online Journal of Educational Sciences. 2013; 5 (2): 409-20.

23. Sarıbaş M, Meydan A. Coğrafya bölümü öğrencilerinin çevrimiçi öğrenmeye karşı tutumları. Türk Coğrafya Dergisi. 2020; 76: 95-106.

24. Hergüner G, Son SB, Hergüner Son S, Dönmez A. The effect of online learning attitudes of university students on their online learning readiness. TOJET: The Turkish Online Journal of Educational Technology. 2020; 19(4): 102-10.

25. Subedi S, Nayaju S, Subedi S, Shah SK, Shah JM. Impact of e-learning during COVID-19 pandemic among nursing students and teachers of Nepal. International Journal of Science \& Healthcare Research. 2020; 5(3): 68-76.

26. Çelik Eren D, Korkmaz M, Öz Yıldırım Ö, Aydın Avci İ. COVID-19 pandemi sürecinde hemşirelik öğrencilerinin uzaktan eğitime karşı tutum ve memnuniyet düzeyleri. Anadolu Hemşirelik ve Sağlık Bilimleri Dergisi. 2021; 24(2): 246-54. https://doi.org/ 10.17049/ataunihem.862820

27. Keskin Kızıltepe S, Kurtgöz A. Hemşirelik öğrencilerinin COVID-19 pandemisi sürecinde aldıkları uzaktan eğitime yönelik tutum ve görüşlerinin belirlenmesi. Uluslararası Sosyal Araştırmalar Dergisi. 2020; 13(74): 558-66.

28. Öztürk D. Uzaktan eğitime hemşirelik eğitimi penceresinden bir bakış. Anadolu Hemşirelik ve Sağlık Bilimleri Dergisi. 2015; 18(3): 229-34. https://doi.org/10.17049/ahsbd.89981

29. Atasoy I, Sütütemiz N. Bir grup hemşirelik son sınıf öğrencisinin hemşirelik eğitimi ile ilgili görüşleri. Florence Nightingale Hemşirelik Dergisi. 2014;22(2):94104.

30. Durgun H, Can T, Avcı AB, Kalyoncuoğlu B. Covid19 sürecinde hemşirelik öğrencilerinin uzaktan eğitime yönelik görüşleri ve kaygı düzeyleri. DEUHFED. 2021; 14(2): 141-7. https://doi.org/10.46483/deuhfed.824109

31. Kürtüncü M, Kurt A. COVID-19 pandemisi döneminde hemşirelik öğrencilerinin uzaktan eğitim konusunda yaşadıkları sorunlar. Avrasya Sosyal ve Ekonomi Araştırmaları Dergisi. 2020; 7(5): 66-77.

32. Kaya Y, Akın Işık R. The contribution and challenges of the implemented compulsory distance education system to nursing education in the first period of the COVID-19 pandemic: A qualitative study. J Educ Res Nurs. $\quad 2021 ; 18$ (Supp. 1): 76-84. https://doi.org/10.5152/jern.2021.67365

33. Özbay Ö, Çınar S. Views of nursing students on distance education. Education Conference. 2020: 37-45.

34. Şenyuva E, Kaya H, Bodur G. Hemşirelik öğrencilerinin web tabanlı bir derse ilişkin görüşleri. Ege Üniversitesi Hemşirelik Fakültesi Dergisi 2017; 33(3): 62-77.
35. McCutcheon K, O’Halloran P, Lohan M. Online learning versus blended learning of clinical supervisee skills with pre-registration nursing students: A randomised controlled trial. Int J Nurs Stud. 2018; 82: 30-9. https://doi.org/10.1016/j.ijnurstu.2018.02.005

36. Gaur R, Mudgal SK, Kaur S, Sharma R. Undergraduate nursing students' attitude towards online classes during lockdown period in India: imposed or interested? Int J Community Med Public Health 2020; 7(9): $\quad 3371-7 . \quad$ http://dx.doi.org/10.18203/23946040.ijcmph20203892

37. Thapa P, Bhandari SL, Pathak S. Nursing students' attitude on the practice of e-learning: A cross-sectional survey amid COVID-19 in Nepal. PLoS One. 2021; 16(6): $\mathrm{e} 0253651$. https://doi.org/10.1371/journal.pone.0253651

38. Akimanimpaye F, Fakude LP. Attitudes of undergraduate nursing students towards e-learning at the University of the Western Cape, South Africa. African Journal for Physical, Health Education, Recreation and Dance. 2015; (Supplement 1:2 (October): 418-33.

39. Ali N, Jamil B, Sethi A, Ali S. Attitude of nursing students towards e- learning. Adv Health Prof Educ. 2016; 2(1): 24-9.

40. Maurya R, Nayok SB, Sathyanarayana MT, Dhanashree Akshatha HS. Acceptability, attitude, and satisfaction of online learning among nursing students during COVID-19 lockdown: A cross sectional study. International Journal of Indian Psychology. 2020; 8(2): 69-76. https://doi.org/10.25215/0802.209 